\title{
Where All Roads End: Photography and Anthropology in the Kalahari - Peabody Museum Press
}

by llisa Barbash

Cambridge, Massachusetts: Peabody Museum Press, Harvard University, 2016,

274 pages

ISBN: 97-808-736-54098 (paperback) Price \$39.95

Reviewed by Patricia Prieto-Blanco, University of Brighton

Ilisa Barbash's profound respect and admiration for the Marshalls' approach to visual anthropology permeates every and each of the pages of Where All Roads End via, what I venture to call, a curatorial approach. This results in a book that works in equal measure as guide and a road map to the particular - the Marshalls' work with the Ju/'hoan, the /Gwi and Naron - as well as a conscientious critical review of how the wider anthropological gaze has rendered Bushmen flat via typology, mythology and iconicity. Context is Barbash's strongest and most effective tool to tackle the intuitive while complex and innovative work of Laurence, Lorna, John and Elizabeth Marshall. Throughout the book, the Marshalls' work is contextualised via the images produced during their eight expeditions to the Kalahari, excerpts from interviews given by members of the Marshall's family, quotes by other expedition members extracted from films and the Peabody Museum Collections, as well as historical documents such as newspaper clippings, maps and illustrations. Where All the Roads End is half book, half collection of annotated resources and as such is essential not only for audiences interested in the representation of southern Africa's people, but also for those working with and teaching visual anthropology, visual research methods and visual cultures.

In the introduction to Where All the Roads End, Paul Theroux points out that Canetti was impressed by one concrete insight elicited by the Marshalls, namely Bushmen's ability of presentiment/precognition. I believe it's important to bring this ability in relation with the Marshall's approach to ethnographic work. The Marshalls were perceived as a family pursuing a project together, or a project of togetherness; and as such they 'were incorporated into the Ju/'hoan kinship system' (xxviii). Arguably, the Ju/'hoan foresaw that Marshalls approach based on human and sensory connection in the field, would considerably advance methodological knowledge in ethnography and anthropology.

Although over 40000 photographs were produced in the eight Marshalls expeditions in the Kalahari, less than 300 have been published. According to Theroux, Barbash's book seeks to remedy this by offering a curated selection of images that reveals both the richness and depth of the Marshalls' engagement with the Ju/'hoan, as well as the 'significance of their pictorial legacy' (xxv). He further explains the images produced by the Marshall family helped to counteract colonialist representation because it captured the Ju/'hoan people in their everyday, while keeping a valuable record of the changes brought by white farmers. In fact, Barbash devoted chapter two to establish that the Marshalls' work is one of the first contributions to the destabilisation of the colonial gaze. Those working in upper secondary education, as well as in further and higher 
education will find that pages 20 to 36 provide the basis for teaching units such as anthropology and photography; history of visual research methods; otherness, race and photography; or white privilege, research and representation. The visual telling of a short but poignant moment of destabilisation in chapter three, when in 1951 John Marshall poses for his own anthropometric photographs, is also a good resource to discuss power and gaze in the classroom. Furthermore, the foreword, the note on terminology and spelling and insert Bushman Nostalgia in chapter nine, are good companions to chapter two as they clearly highlight the visual, cultural and discursive structures that the West has been imposing for centuries onto many, and specifically onto the 'traditionally peace loving, communal minded, and cooperative' (xiv) Ju/'hoan.

An important question that All the Roads Ends could have addressed more thoroughly is that of the authorship of the photographs. The role and impact of technology on the images is reviewed in chapter four via a focus on production with sections dedicated to cameras, as well as to particular photographers. Chapter five extends it to the process of production. Those interested in the anthropology of material culture as well as in the question of distributed agency between human and no-humans, will find this chapter illuminating. The section dedicated to Annelise Fuss-Hippel Scherz, the only female and professional photographer ever hired by the Marshalls, could have included a more depth discussion of copyright and collaboration between ethnographers/anthropologists and professional visual makers. Even today, established understandings of participatory research often neglect, or ignore, the role of other professionals - camera crews for instance - in the production of outputs.

Throughout chapters four, six and nine, Barbash argues that the family working modus allowed for novel perspectives and aesthetics to emerge, which challenged normative representations of Bushmen and established ethnographic methods. The running thread through these three chapters is a detail exploration of the Marshalls' approach to visual anthropology. Barbash explains how their self-taught research skills, visual and otherwise, were influenced by contemporary documentary work and photojournalism, and how the Marshalls' holistic, intuition-lead and experienced-centered approach to inquiry allowed for everyday, even intimate, moments to be observed and captured. In a similar fashion to Margaret Mead in Bali, whom the Marshalls turned for advice and discussion, 'the family relied heavily on the practice of photography itself to gather information' (133) Both bodies of work heavily influenced the then nascent field of visual anthropology partially because '[t]he selections of individual subjects, activities, camera angles, composition, film stock, and whether to photograph (and/or publish) in color or in black and white all reveal their authors' hands' (ibid.) and thus steered away from the systematic classifications that had driven European and American inquiries for over a century.

The collection of images included in Where All the Roads End is a testament to both the Marshalls' dynamic way of doing visual anthropology, as well as to Barbash's intimate knowledge of the 40000 image collection and of the discipline at large. Her curatorial 
approach reveals an intergenerational research project that continues to illuminate visual ethnographers and anthropologists alike. The force of the Marshalls' work is powerfully reproduced in this book via a detailed, intimate and aesthetically pleasing encounter with their images.

Beyond the productive discussions the Marshalls' work has generated and still propels today, it is very important for the story of this self-taught family of anthropologists to be told again as it recalls the need for openness and scholarly ability to listen, as well as of a certain institutional disposition to foster innovation, if we are to truly advance visual studies pragmatically and ontologically. Where All the Roads End is a testimony to the willingness of academics to value projects ideas foremost and credentials later, which somehow reminds me more of contemporary activism than of neoliberal academia. 